\title{
Basics of Color in Dentistry: A Review
}

\author{
Dr. Rakesh Vadher ${ }^{1}$, Dr. Girish Parmar ${ }^{2}$, Dr. Shikha Kanodia ${ }^{3}$, \\ Dr. Akashi Chaudhary ${ }^{4}$, Dr. Manjit Kaur ${ }^{5}$, Dr. Toral Savadhariya ${ }^{6}$ \\ I'Department of Conservative Dentistry and Endodontics, Govt. Dental College \& Hospital, Ahmedabad, India) \\ ${ }^{2}$ (Dean \& HOD, Department of Conservative Dentistry and Endodontics, Govt. Dental College \& Hospital, \\ Ahmedabad, India) \\ ${ }^{3}$ (Assistant Professor, Department of Conservative Dentistry and Endodontics, Govt. Dental College \& \\ Hospital, Ahmedabad, India) \\ ${ }^{4}$ (Department of Conservative Dentistry and Endodontics, Govt. Dental College \& Hospital, Ahmedabad, India) \\ ${ }_{5}^{5}$ (Department of Conservative Dentistry and Endodontics, Govt. Dental College \& Hospital, Ahmedabad, India) \\ ${ }^{6}$ (Intern Dentist, Govt. Dental College \& Hospital, Ahmedabad, India)
}

\begin{abstract}
Think of the world without the color. Color can turn everything, even the unsightly, into a visual pleasure. Properly used, color creates atmosphere, defines space and proportion, establishes order and exudes emotion. To perceive all these one has to have the so-called color sense. (i.e. the ability to make the right color choice). Colored restoration or prostheses should impart the translucency and fluorescence of natural dentition, and reproduce the opacity and vitality of natural tooth structure. The practicing dentist apparently accommodates to the environmental influences of light and color in his surroundings to the extent that he is able to correct the color of the restoration or prosthesis to his own satisfaction and to that of his patients. In esthetic dentistry, the focus is on merging function and beauty with the values and the individual needs of the patient. The color of a restoration or prosthesis to surrounding teeth may be the only parameter of treatment with which the patient is concerned. It is often media driven and can result in a desire for excessively white and bright natural teeth that enhance the face, but do not attract unwarranted attention.
\end{abstract}

Keywords: chroma, color vision, eye, hue, light, color vision

\section{Introduction}

Different clinicians may vary in their ability to detect small differences in color between two objects [1-3]. Now a days instrumental color measurement in dentistry helps in shade selection using intra oral optical electronic determination of a target color during fabrication of a restoration [4]. Color perception also might differ for the same person under different conditions [3]. However, sometimes it happens that observers detect a color difference between two objects; their opinions might differ to some extent [5]. Clinicians were more serious of crowns in which color differed in redness as opposed to in yellow color [1].

\section{Nature Of Color}

Color is explained by making reference to a sensation which is captured by our eyes. The human eye is an organ that is receptor of images obtained from an electromagnetic radiation that we refer to as light. It actually corresponds to a narrow segment between the 400 and $800 \mathrm{~nm}$ wavelengths approximately of the entire spectrum. We call it as rainbow.

When white light is illuminated to object, the color we see has not been absorbed and that light is reflected to our eyes is color is object. So this fact tells us that the quality of light plays an important role in perception of color of an object. [6]

\section{Measurement Of Color}

Measurement of color is major problem not only limited to dental profession but it is also seen in other fields like industries and medicine.

\subsection{Munsell color order system}

Many color order systems are available, but for a variety of reasons, including worldwide recognition, consistency, flexibility and simplicity, the Munsell color order system is the system of choice for color matching in dentistry. The color tree is a representation of the tridimensional organization of colors within the Munsell system. The Munsell color solid can be likened to a sphere or a cylinder, as it is an irregular three dimensional figure that has characteristics of both. A colorless or achromatic axis extends through the centre of the cylinder. Pure white is at the top and pure black at the bottom. A series of grays, progressing from black to white in equal 
visual steps connects these extremities. Hues are arranged sequentially around the rim. The spokes represents the gradations of chroma from the colorless axis to the purest hue at the rim.

There are usually three traditional dimensions of color:

\subsubsection{HUE}

Hue, tonality: it is referred to as color of an object. Hue is directly related to the wavelength of the luminous radiation observed (e.g. violet, indigo, red, green, blue, yellow, etc....).

Hue is the quality that distinguishes one family of colors from another. It is specified as the dominant range of wavelengths in the visible spectrum that yields the perceived color, even though the exact wavelength of the perceived color may not be present. Hue is a physiologic and psychological interpretation of a sum of wavelengths. In dental terms, hue is represented by A, B, C, or D on the commonly used Vita Classic shade guide.

\subsubsection{VALUE}

Value, luminosity: it shows the amount of light that makes black and white image of the observed object, ranging from a maximum value, white, and a minimum value, black.

Value, or brightness, is the amount of light returned from an object. Munsell described value as a white to- black gray scale. Bright objects have lower amounts of gray, and low-value objects have larger amounts of gray and will appear darker. The brightness of a crown is usually increased in two ways: by using lighter porcelain (lowering chroma), or by increasing the reflectivity of the surface. Lowering value means diminished light returns from the object illuminated; more light is being absorbed, scattered elsewhere, or transmitted through.

\subsubsection{CHROMA}

Chroma, saturation: it shows the amount of dye that the color contains the chromatic brightness that we observe. This dimension depends on the different dilutions of the base color we are starting from. [7]

Chroma is the saturation, intensity, or strength of the hue. Envision placing red food dye into a glass of water. Each time more of the same color dye is added, the intensity increases, but it is the same red color (hue). As more dye is added, the mixture also appears darker, so the increase in chroma has a corresponding change in value. As chroma is increased, the value is decreased; chroma and value are inversely related. Higher numbers on the Vita Classic shade guide represent increased chroma.

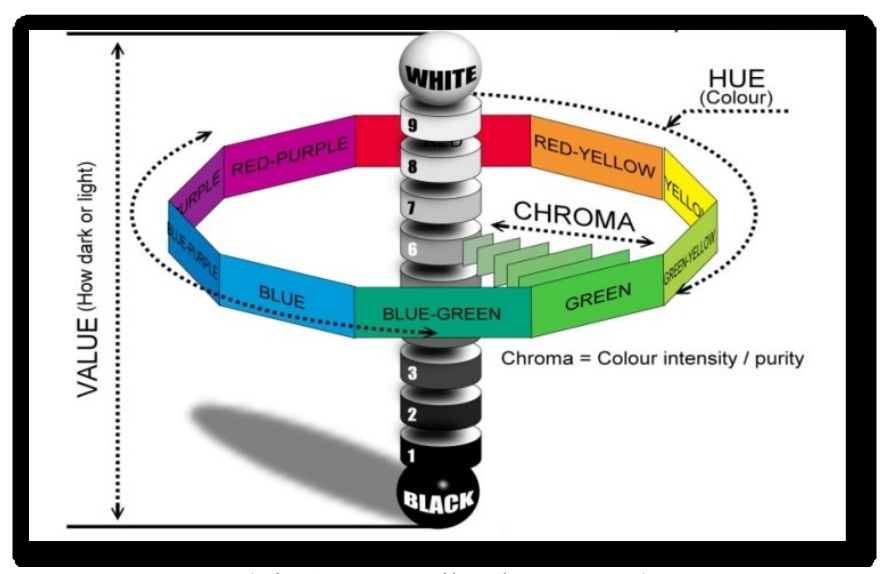

(Fig 1: Munsell color system)

\subsection{CIE Lab color system and color space}

The commission International de I'Eclairage (CIE), an organization devoted to standardization in areas such as color and appearance defined in 1931 a standard light source, developed a standard observer and enabled the calculation of tristimulus value, which represent how the human visual system responds to a given color. In 1976, the CIE further defined a color space, CIE Lab, that supports the accepted theory of color perception based on three separate color receptors in the eye and is currently one of the most popular color spaces. [8] 


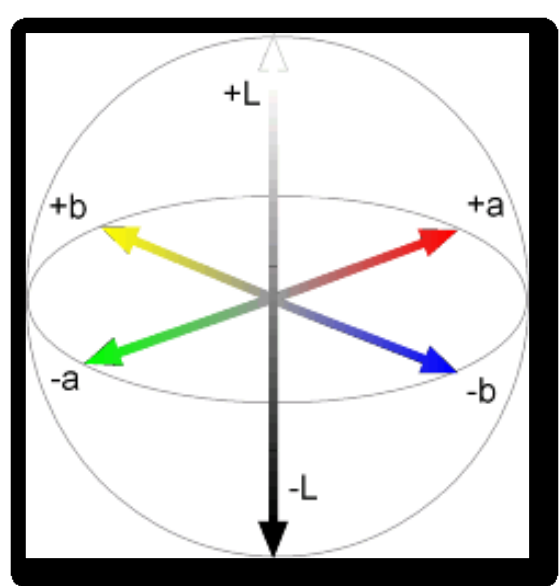

(Fig 2: CIE LAB)

The CIE color space represents a uniform color space, with equal distances corresponding to equal perceived color differences. In this three dimensional color space the three axis are $\mathrm{L}^{*}, \mathrm{a}^{*}$ and $\mathrm{b}^{*}$. The $\mathrm{L}^{*}$ value is a measure of the lightness of an object and is quantified on a scale such that a perfect black has an $\mathrm{L}^{*}$ value of 100. The $a^{*}$ value is a measure of redness (Positive $a^{*}$ ) or greenness (negative $a^{*}$ ). The $b^{*}$ value is a measure of yellowness (positive $b^{*}$ ) or blueness (negative $b^{*}$ ). The $a^{*}$ and $b^{*}$ co-ordinates approach zero for natural colors and increase in magnitude for more saturated or intense colors. The advantage of the CIE Lab system is that color differences can be expressed in units that can be related to visual perception and clinical significance.

\subsection{Translucency}

\section{Properties}

In dental ceramics, we try to duplicate the appearance of the tooth as a addition of all its visual dimensions. Human teeth are characterized by varying degrees of translucency, which can be defined as the slope between transparent and opaque. In general, increasing the translucency of a crown lowers its value because less light returns to the eye. With increased translucency, light is able to go by the surface and is scattered within the body of porcelain. The translucencies of enamel differ with the angle of incidence, surface texture and luster, wavelength, and level of dehydration.

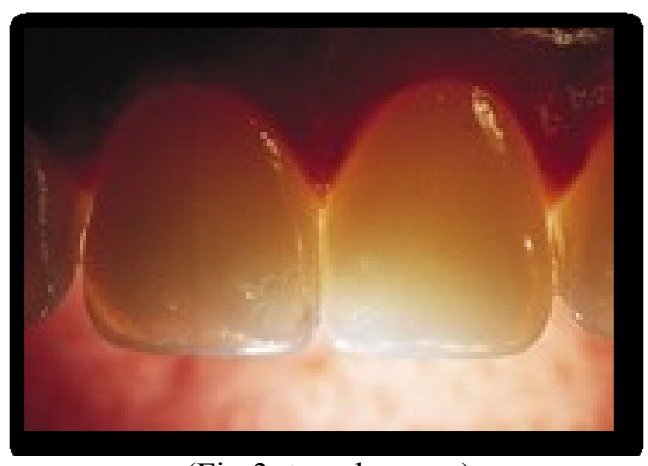

(Fig 3: translucency)

\subsection{Fluorescence}

Ultraviolet (UV) light gives a striking effect on the level of vitality exhibited by restorations. Fluorescence is the absorption of light by a material and the spontaneous emission of light in a longer wavelength. [9] In a natural tooth, it primarily occurs in the dentin because of the higher amount of organic material present. [10-13] Ambient near-UV light is absorbed and fluoresced back as light primarily in the blue end of the spectrum, but it will occur at all wavelengths. The more the dentin fluoresces, the lower the chroma. $[10,14]$ Fluorescent powders are added to crowns to increase the quantity of light returned back to the viewer, block out discolorations, and decrease chroma.[14] 


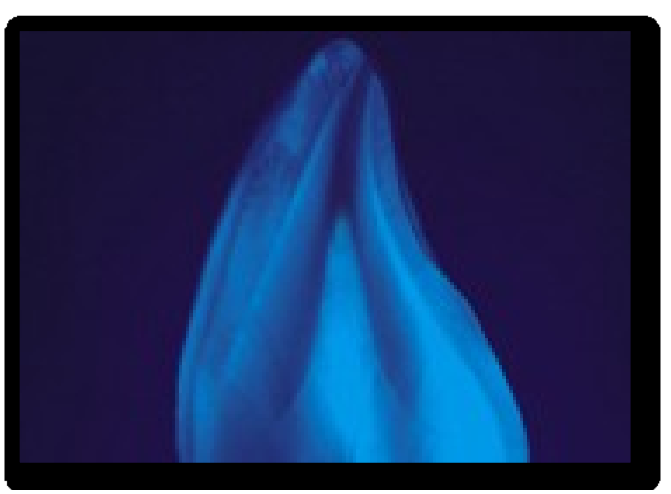

(Fig 4: fluorescence)

\subsection{Opalescence}

Opalescence is the fact in which a material appears to be one color when light is reflected from it and another color when light is transmitted through it.[15] A natural opal is an aqueous disilicate that splits transilluminated light down into its component spectrum by refraction. When illuminated, opals and enamel will trans illuminate the reds and scatter the blues within its body; thus, enamel appears bluish even though it is colorless. [10, 11, 16] The opalescent effects of enamel brighten the tooth and give it optical depth and vitality.[17]

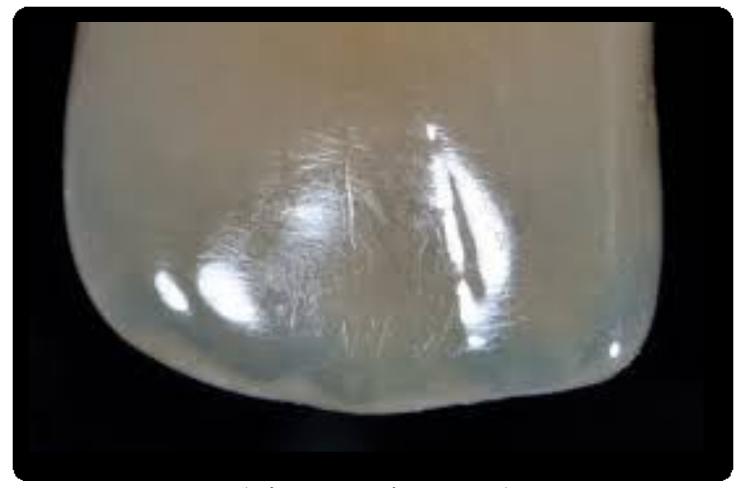

(Fig 5: opalescence)

\subsection{Contrast and glare}

Contrast is originated by a differentiation between the brightness or color of an object and its immediate background. Object forms with high contrast are easier to choose than objects with low contrast. While some contrast is supportive, excessive contrast causes glare. An exceedingly bright object against a dark background or significantly differently colored objects cause embarrassment and can interfere with perception.[10, 18] This interference is called glare. The illumination of the teeth should not be significantly brighter than the ambient environment. [19] With dental photography, the use of a black background increases impact, but it will cause glare.

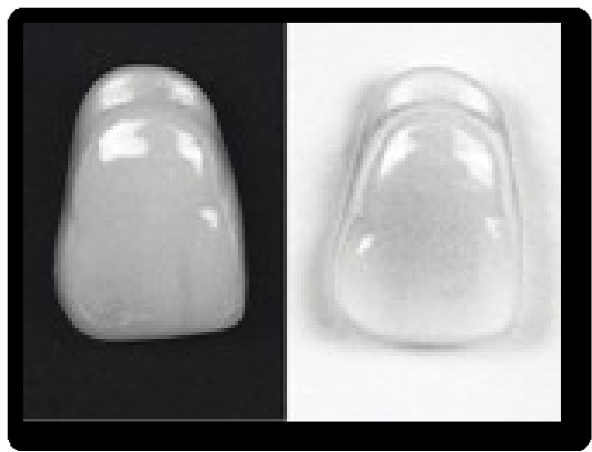

(Fig 6: Contrast) 


\subsection{Color perception}

Color perception depends fundamentally on human physiology. Humans have three types of coneshaped receptor cells, each sensitive to one of the three primary colors of light (red, green, and blue). Impulses from the three types of receptor cones are thought to combine into a coded signal. The combination takes place in the ganglion cells in the retina. Changes in the color stimulus change the patterns of the coded signals. [18] Two lights of different colors, when mixed, produce a third color, and no human eye can detect its composite nature. Ultimately, the perceived hue is the dominant or average wavelength.

\subsection{Afterimage and visual distortion}

Afterimages are frequent physiologic effects of the cone receptors with normal function that cause alterations in perceptions. One type of afterimage that commonly affects clinicians is the spreading effect that occurs when light is removed from the retina; the receptors continue for a short time to be active and send a signal to the brain. [10] If presented simultaneously with two adjacent areas of different color, the eyes will flick back and forth between them involuntarily. The color seen for each is a combination of two colors. When holding a shade guide close to a tooth, it is important to decide within seconds because the two will soon begin to appear more and more alike. [19]

A negative afterimage occurs because of fatigue of the cone receptors, which become less sensitive to further stimulation. Strong red lipstick next to the tooth being evaluated will fatigue the red receptors in the roaming eyes, while the blue and green receptors remain fresh and can be fully stimulated. This can yield a perception of the tooth that is too blue-green. Give the eyes a break with neutral gray backgrounds. Kulzer's small intraoral gray cardboard Pensler shields screen background color glare; $18 \%$ reflective gray cards are the photographic industry standard achromatic background. [20] Blue backgrounds are not right because they cause afterimages and will bias perception to the complementary color, orange. Some believes use of a blue background [21-24] to make the eyes more sensitive to yellow-orange, but this selectively fatigues one type of cone and does not make the others any more sensitive. An 18\% reflective gray card is an excellent background for photographic evaluation of hue and chroma.[25]

\section{The Human Eye As Receiver Of Color}

The perception of color may get altered by specific chromatic appreciation problems such as daltonism, which creates itself basically in the confusion of the colors red and green [26], and others. This needs to be identified by the practitioner, for example the variation of the perception of color between both eyes. We need to see the color by opening both eyes, seeing that there can be notable dissimilarities in the perception of each one of the eyes independently. In this affair, the practitioner suffers from one of these problems; he should take suitable measures, such as delegating the dimension of color to auxiliary team with a normal chromatic vision if the alteration is permanent.

Avoiding as much as possible the intake of materials that can modify perception, such as alcohol and morphine, which lighten the warm colors (yellow, orange, red) and darken the cold ones (purple, green, blue); caffeine, which darkens warm colors and lightens cold ones; or in the case of drugs such as Viagra ${ }^{\circ}$, which modifies chromatic perception giving a blue tint to colors; contraceptives, which can at times induce difficulty in discriminating red-green or blue-yellow.

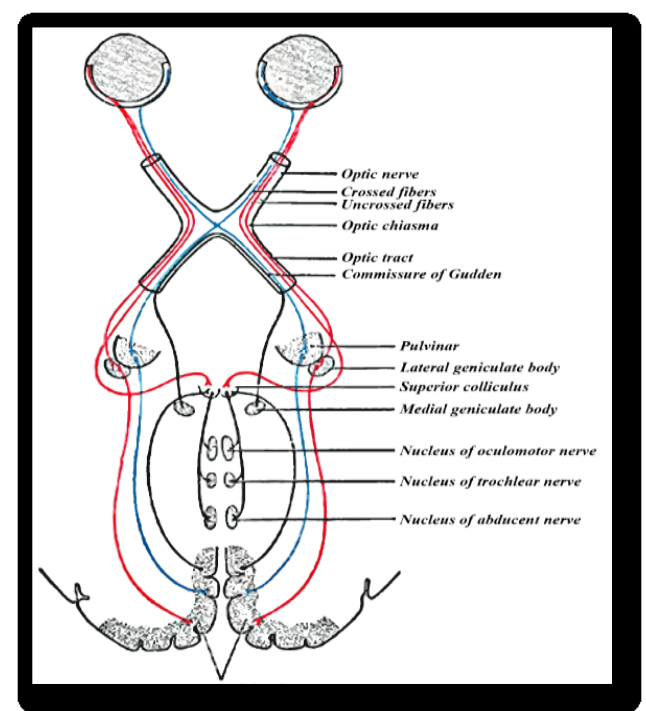

(Fig 7: human visual pathway) 


\section{Light From Environment}

Since the human vision route requires three essentials (light, object and receiver). And we assume that the receiver is functioning properly, i.e., no chromatic perception pathology exists; let us concentrate on the influence of light in the measurement of color.

The nature of the light source in the clinic is essential. In fact, its spectrum will influence chromatic appreciation in a critical way. The ideal light for color measurement is that which is closest to the light spectrum of daytime sunlight. Since this is not always possible in all dental clinics because not all the clinics have access to this ideal natural light, and because at certain hours of the day, or at certain seasons of the year, daylight is insufficient, we must use artificial light sources.

In this case the use of incandescent light sources such as common or halogen light bulbs must be avoided, since they emit a spectrum with a greater proportion of colors close to red, which can alter chromatic appreciation. The environmental lighting of the clinic must be used, and the use of the light sources known as "day" light sources is recommended. The corrected fluorescent light sources which present color temperatures of between $5,000^{\circ}$ and $6,500^{\circ} \mathrm{K}$ are suggested. These lights are suitable for all processes that require a correct chromatic perception.

At the present time, the "Shade Light TM" (KERR), Rite-Lite (ADDENT) lamp is on the market, offering D65 and D55 light respectively that provides ideal observation conditions, and given its relatively low cost and ease of use, it is feasible for a great number of professionals [27, 28].

\section{Proper Environment For Color Rendering}

The skill to perform shade selection depends on how well the eyes perceive the details of teeth. Many factors determining the visibility of these details include ambient light quality, luminance, size, contrast, and gloss. Dental-unit lights are frequently used for color rendering. Most commonly used lights are incandescent and emit light high in the red-yellow spectrum and low at the blue end.

The translucency of enamel is a because of wavelength. The longer the wavelength, the higher is the translucency. Therefore, enamel is more translucent in light rich in yellow and red (eg, incandescent light) and will show more dentin, making the tooth appear redder, with a higher chroma and lower value than it actually has.[29] The ambient light quality of the operatory must be maintained with artificial lighting (natural light conditions vary); it is commonly measured by the color temperature and Color Rendering Index (CRI).

CRI is the measure of the completeness of the light spectrum. A measure of 100 indicates that the entire visible and near-UV light spectrum is present. The average incandescent dental-unit lamp has a CRI of 75 and averages $3,800 \mathrm{~K}$. A CRI greater than 93 is preferred. Ideally, both the clinician and laboratory technician should have balanced full-spectrum lighting conditions.

Color temperature is defined as mean wavelength of the ambient light. The ideal color temperature for color rendering is $5,500 \mathrm{~K}$. Light at this temperature can be described as having a medium-temperature feel and is considered "white" light. Ambient light is a varying assembly of many different wavelengths. Artificial lighting can approach white light $(5,500 \mathrm{~K})$, but the full spectrum of wavelengths is not necessarily present. The reflected colors (wavelengths) of a tooth cannot be seen if those wavelengths are not present in the ambient light spectrum.[30,22]

\section{Metamerism}

Metamerism occurs when restorations match in one light but display a different color in other light conditions. [25] The color seen depends on the nature of the light source illuminating the object. The color of an opaque object is the sum of the wavelengths that reflect off it. Porcelain might reflect light from its surface exactly as enamel in one part of the spectrum, but under dissimilar illumination the two objects that previously looked identical might look different. The closer the curves of the two materials to be matched, the more successful the color match will be. [31] Use of opaque surface stains for porcelain teeth to correct mismatches will increase metamerism.

\section{Color Vision Deficiencies}

Color vision deficiencies are a cluster of conditions that affect the acuity of color [32]. They can be inherited or acquired. Acquired color vision defects are caused by toxins, inflammation or detachment of the retina, ageing and many other causes [33]. The problem typically occurs in all the cones and the central pathways from the eye to the brain.

Color vision defects grounds a range of changes in color vision, from mild difficulty with distinguishing shades to a total inability to detect color. These conditions are separated into three major categories: red-green color vision defects, blue-yellow color vision defects, and a complete absence of color vision [34-40]. 
Blue-yellow color vision defects affect males and females uniformly. This situation occurs in fewer than 1 in 10,000 people worldwide [41,42]. An absence of color vision is called achromatopsia. They see only black, white, and shades of gray [43]. People with achromatopsia almost always have additional problems with vision including reduced visual acuity, increased sensitivity to light (photophobia), and small involuntary eye movements called nystagmus [43].

Tests for color blindness Ishihara test Professor Holmgren's test

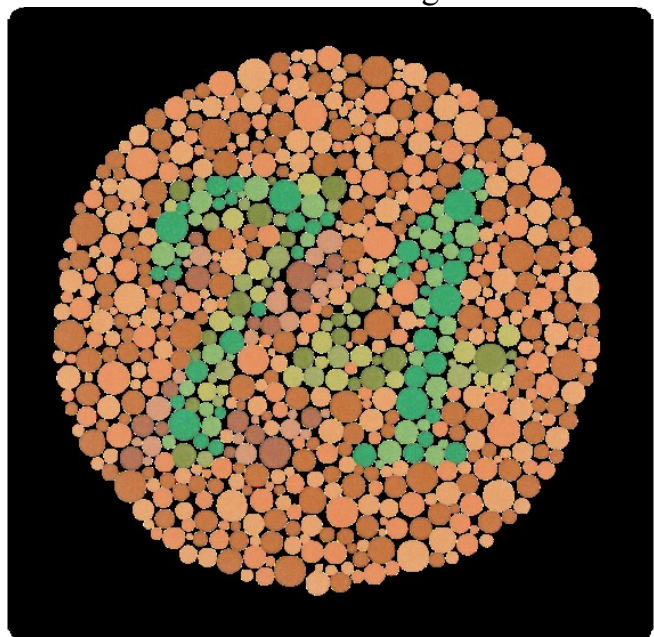

(Fig 8: Ishihara chart)

Consequently, selecting the proper porcelain shade and matching restorations to the natural dentition continue to be challenges for the restorative dentist. The process of shade selection is an art in which the dentist and patient should collaborate. Dentists may consider changing a restoration because they believe the color does not match that of the adjacent teeth, even though the color difference might not be noticeable to the patient. Involving the patient in the shade selection process likely will improve his or her satisfaction with the final outcome.

To date, patient satisfaction with shade matching or patient input into the shade selection process has not been appraised carefully in the dental literature.

\section{Implication Of Basics Of Color In Dentistry}

Each individual perceives color differently. So it is very important to understand basics of color. There are several factors that can influence the dental professional's color assessment. When using traditional shadematching techniques, there are several variables that the dental professional should consider. When tooth shade is selected properly, it gives efficient results and satisfaction to dentists and patients both

\section{References}

[1] Brown WRJ. Color discrimination of twelve observers. J Opt Soc Am. 1957;47 (2):137-143.

[2] Wyszecki G, Fielder GH. Color-difference matches. J Opt Soc Am. 1971;61(11):1501- 1513.

[3] Culpepper WD. A comparative study of shade-matching procedures. J Prosthet Dent. 1970;24(2):166-173.

[4] Douglas RD, Brewer JD. Acceptability of shade differences in metal ceramic crowns. J Prosthet Dent. 1998;79(3):254-260.

[5] Johnston WM, Kao EC. Assessment of appearance match by visual observation and clinical colorimetry. J Dent Res. 1989;68(5):819-822.

[6] Miller L. Organizing color in Dentistry. J Am Dent Assoc 1987;115: 26E-40E

[7] Chu J, Devigus A, Mieleszko A. The physics of color en Fundamentals of color: Shade Matching and comunication in esthetic dentistry (Ed Quintessence Chicago; 2004). p. 3-17

[8] Yiu H. Hui Handbook of Food Science, Technology, and Engineering (Volume 2, CRC Press, US), 2006, 62-1-62-6

[9] McLaren E. Luminescent veneers. J Esthet Dent 1997;9:3-12.

[10] Overheim D. Light and Color (New York: John Wiley), 1982.

[11] Winter R. Visualizing the natural dentition. J Esthet Dent 1993;5:103-117.

[12] Cornell D, Winter R. Manipulating light with the refractive index of an all-ceramic material. Pract Periodontics Aesthet Dent 1999;11:913-917.

[13] Orban BJ. Oral Histology and Embryology (ed 6). (St Louis: Mosby), 1976.

[14] McLaren E. The 3D-master shade-matching system and the skeleton buildup technique: Science meets art and intuition. Quintessence Dent Technol 1999;22: 55-68.

[15] Sundar V, Amber PL. Opals in nature. J Dent Technol 1999;16:15-17.

[16] Ten Bosch JJ, Coops JC. Tooth color and reflectance as related to light scattering and enamel hardness. J Dent Res 1995; 74:374 380 .

[17] Garber DA, Adar P, Goldstein RE, Salama H. The quest for the all-ceramic restoration. Quintessence Dent Technol 2000; $23: 27-36$.

[18] Rainwater C. Light and Color. (Racine, WI: Golden Press), 1971:100-118.

[19] Preston JD, Ward LC, Bobrick M. Light and lighting in the dental office. Dent Clin North Am 1978;22:431 451. 
[20] Pensler AV. Shade selection: Problems and solutions. Compend Contin Educ Dent 1998;19:387-396.

[21] Sproull R. Color matching in dentistry. Part I. J Prosthet Dent 1973;29:416-424.

[22] Glick K. Color and shade selection in cosmetic dentistry: Part III. Establishing the proper environment and technique. J Am Acad Cosmet Dent 1994;10:14-20.

[23] Mathews TG. A method for shade selection. Quintessence Dent Technol 1980; 11:101-105.

[24] Miller LL. Esthetic dentistry development program. J Esthet Dent 1994;6:47-60.

[25] Pensler AV. Photography in the dental practice. Quintessence Dent Technol 1983;14:855-858.

[26] Wasson W, Schuman N. Color vision and dentistry. Quintessence Int 1992;23:349-53

[27] Chu J, Devigus A, Mieleszko A; Elements affecting color en Fundamentals of color: Shade Matching and comunication in esthetic dentistry (Ed Quintessence Chicago); 2004. p. 40-3

[28] Belvedere Paul. Matching One Natural Tooth for the Creation of a Ceramic Restoration. Available from http://www.kerrdental.com/images/products/demetronShadeLightLED1/pdf/backToTheBasics.pdf

[29] O'Brien W. Double layer effect and other optical phenomena related to esthetics. Dent Clin North Am 1985;29:667-673.

[30] Rossing TD, Chiaverina CJ. Light Science: Physics and the Visual Arts (New York: Springer), 1999

[31] Sproull R. Color matching in dentistry. Part III. Color control. J Prosthet Dent 1974;31:146-154.

[32] Foster, D. H. Inherited and acquired color vision deficiencies: fundamental aspects and clinical studies (Macmillan Press: London); 1991.

[33] Cohen J. Weighted kappa: nominal scale agreement with provision for scaled disagreement or partial credit. Psychol Bull. 1968:70:213-220.

[34] Fleiss JL. Statistical methods for rates and proportions (2nd ed.) (New York: Wiley); 1981. p. 119-123.

[35] Bross IDJ. How to use ridit analysis. Biometrics. 1958;14(1):18-38.

[36] Wasson W, Schuman N. Color vision and dentistry. Quintessence Int. 1992;23(5):349-353.

[37] Yorty JS, Richards MW, Kanawati A, Davis S, House RC, Okubo SR. A simple screening test for color matching in dentistry. Gen Dent. 2000;48(3):272-276.

[38] Al-Aqtum MT, Al-Qawasmeh MH. Prevalence of color blindness in young Jordanians. Ophthalmologica. 2001; 215(1): 39-42.

[39] Al-Wahadni A, Ajlouni R, Al-Omari Q, Cobb D, Dawson D. Shade-match perception of porcelain-fused-tometal restorations. A comparison between dentist and patient. J Am Dent Assoc .2002;133(9):1220-1225.

[40] Cole BL. Assessment of inherited color vision defects in clinical practice. Clin Exp Optom. 2007;90(3):157 175.

[41] Color vision defect and tooth shade selection among Nigerian dental practitioners Rev. Clín. Pesq. Odontol. 2007 set/dez;3(3):175182182

[42] Weitz CJ, Miyake Y, Shinzato K, Montag E, Zrenner E, Went LN, et al. Human tritanopia associated with two amino acid substitutions in the blue-sensitive opsin. Am J Hum Genet. 1992;50(3):498-507.

[43] Weitz CJ, Went LN, Nathans J. Human tritanopia associated with a third amino acid substitution in the blue-sensitive visual pigment. Am J Hum Genet. 1992;51(2):444- 446.

[44] Sharpe LT and Nordby K. Total color blindness: an introduction (Cambridge University Press: Cambridge); 1990. p. $253-289$. 